\title{
Influences on youthful driving behavior and their potential for guiding interventions to reduce crashes
}

\author{
J T Shope
}

Injury Prevention 2006;12(Suppl I):i9-i14. doi: 10.1136/ip.2006.011874

Correspondence to: Dr J T Shope, University of Michigan, Transportation Research Institute and School of Public Health, Ann Arbor, Michigan, USA, 2901 Baxter Road, Ann Arbor, Ml 481092150, USA; jshope@ umich.edu

Accepted 24 April 2006
This paper presents an organized, comprehensive view of the factors known to influence young drivers' behavior and how those factors might inform interventions to reduce crashes. This effort was done from the perspective of a public health professional, with a background in health behavior and health education, interested in preventing injury and death among young people from motor vehicle crashes. The author's own studies, selected relevant literature, observation, and experience were considered and organized. A framework of six categories of influences on youthful driving behavior was developed, including the following elements: driving ability, developmental factors, personality factors, demographics, the perceived environment, and the driving environment. It is apparent that a complex set of many different factors influences young drivers' behavior. To reduce crashes, comprehensive, multilevel interventions are needed that target those factors in the framework that are amenable to change. d spite of recent improvements attributed to graduated driver licensing, ${ }^{1}$ young drivers' high rates of traffic crashes, injuries, and fatalities, ${ }^{2}$ and the high monetary costs of crashes ${ }^{3}$ are clearly unacceptable. Young people today are driving in a more complex traffic environment than ever before. There are more cars, more congestion, more complex intersections and roadways, and today's drivers are considered by many to be more rude, aggressive, and distracted. In spite of safer vehicles and roadways, driver behavior remains frustratingly less than ideal. Traffic enforcement alone can never adequately control driver behavior-officers cannot be in all places at all times. Novice drivers are influenced by the complexity of this environment as well as the many other factors in their lives.

This paper will first briefly review some key aspects of the young driver crash problem. Then, many different influences on young drivers will be identified and grouped within a conceptual framework. Based on this framework, interventions to reduce young drivers' crashes can be identified. Potential areas for new or improved interventions for crash reduction will be suggested to guide future work. This paper is not a systematic, critical literature review, but rather a synopsis of the state-of-the-art research based on selected recent studies by the author and colleagues, as well as others in relevant fields. While based primarily on the United States' experience, the approach taken fits, to varying extents, the situation in any developed country. For developing countries that are seeing increasing ownership and use of motor vehicles, considering the US experience could help them to develop successful prevention strategies before young drivers are killed and injured at high rates.

\section{BACKGROUND}

A few aspects of the young driver problem bear mentioning, although they are treated in more depth elsewhere. Teen drivers have the highest crash rate per miles driven of any age group (although the very oldest drivers may be reaching similar levels), and among teens, the youngest teens have the worst crash rate. ${ }^{5}$ Crash rates are lower with each year of increasing age, but not until age 25-30 does the rate level off to that seen throughout most of adulthood. Fatality numbers are high, especially for male drivers, ${ }^{5}$ and injury rates are much higher. ${ }^{5}$ The crash risk for young drivers is higher at night than for more mature drivers. ${ }^{6}$ The risk for this group, especially the youngest teens, is also higher with increasing numbers of passengers present, while it is not higher for more mature drivers. ${ }^{6}$ Young drivers who had been drinking alcohol are overrepresented in fatal crashes well into adulthood (particularly male drivers). Teens are especially vulnerable to the effects of alcohol for several reasons. Their crash risk increases more steeply with increasing blood alcohol levels. ${ }^{6}$ At all blood alcohol levels, teens' crash risk is higher, especially at low and moderate blood alcohol levels. ${ }^{7}$ And teens are relatively inexperienced at driving, drinking, and driving after drinking.

These data clearly indicate a serious public health problem, one that is very complex when all its influences are considered, and one that is challenging to resolve. It is essential, therefore, to understand the big picture of multiple influences before the best and most promising interventions can be developed to reduce youthful driver crashes. To influence behavior successfully, interventions must be grounded in behavioral science theory. While several theories can and have been applied to driving behavior, three theories are particularly useful in understanding youthful driving behavior. Social Learning Theory is based on the fact that we behave in ways we have learned by receiving positive reinforcement, while Social Cognitive Theory employs a dynamic, reciprocal model in which behavior, personal factors, and environmental influences all interact. ${ }^{8}$ Problem Behavior Theory has demonstrated in adolescents and young adults that while behavior is influenced by multiple factors, behaviors viewed as problems sometimes serve a developmental purpose. ${ }^{9}$ The conceptual framework described below draws from these theories.

The outcome of interest in this framework is driving behavior. In order to prevent fatalities from crashes involving young drivers, injuries from those traffic crashes must be prevented, and in order to prevent injuries from those traffic crashes, the traffic crashes themselves must be prevented. While there has been excellent progress in engineering approaches to vehicle safety and roadway design, driver behavior remains a major challenge in preventing traffic

Abbreviations: GDL, graduated driver licensing. 


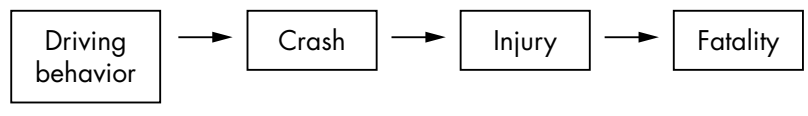

Figure 1 Conceptual framework.

crashes (fig 1), and thus is the focus of the larger conceptual framework to be described below.

\section{CONCEPTUAL FRAMEWORK OF INFLUENCES ON YOUTHFUL DRIVING BEHAVIOR}

The manner in which young people drive is influenced by many different factors. For the purpose of discussion, these factors will be grouped into the categories shown in an overview in figure 2, and discussed in more detail later (fig 3 ). First, the particular driving behaviors of interest need to be specified. Then, the various factors that are seen to affect youthful driving behavior need to include driving ability, physical, social, and behavioral development, personality, demographic factors, the perceived environment, and the driving environment. The relationships between many of these factors and driving behavior have been clarified in research studies. Each factor will be discussed in some detail, beginning with the driving behavior itself.

\section{Driving behavior}

Several driving behaviors seem particularly common in the crashes of young drivers, but are not the only behaviors that could lead to crashes. These behaviors, individually or as a group, need to be modified by interventions in order to reduce crashes and crash related injuries. Young drivers put themselves and others at risk by tending to speed, follow vehicles too closely, make illegal lane changes, and weave through traffic. ${ }^{10}$ Young drivers also, more frequently than more mature drivers, fail to yield the right of way at controlled intersections (yield signs, stop signs, and traffic lights). ${ }^{10-12}$ Young, inexperienced drivers are also less likely to perceive hidden traffic risks and react to them appropriately. ${ }^{13}$

Impaired driving after drinking (and less often after using drugs) is more commonly a young adult driver problem, with alcohol related crash rates demonstrating that finding. ${ }^{5}$ Impaired driving can also be due to fatigue or distraction. Drowsy or sleepy driving due to fatigue is more common among young drivers than mature drivers. ${ }^{6}$ Most adolescents do not get enough sleep, and that sleep loss interferes with their functioning. ${ }^{14}$ Lifestyle issues can be involved as well.

Young novice drivers also seem more easily distracted from the driving task and are inexperienced at judging the driving demand in relation to additional tasks. ${ }^{15}$ The use of cell phones, radio and CD players, as well as eating, drinking, smoking, or interacting with passengers, are other sources of distraction that young novice drivers may not have adequate experience to handle while driving.

Young drivers and passengers also put themselves at greater risk of injury in crashes by wearing their safety belts less often than more mature drivers and passengers. ${ }^{5}$ The

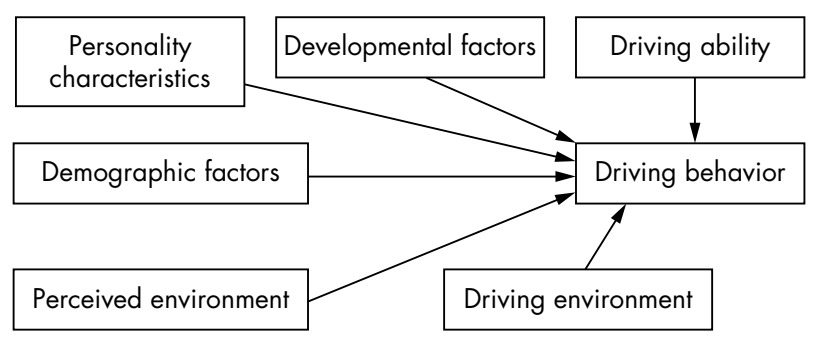

Figure 2 Overall influences on youthful driving behaviour. reasons for this lack of utilizing a proven safety measure are not entirely clear.

\section{Driving ability}

A basic ability to drive is certainly necessary for a person to drive and avoid crashes. This ability is acquired through knowledge, skill development, and experience. All new drivers must acquire knowledge of the rules of the road and how a vehicle works. This knowledge is often gained in a driver education or driver training class, with some behindthe-wheel learning. Driver education is currently under scrutiny as the need for a more science based approach is acknowledged..$^{16}$ In addition to the necessary knowledge, basic skills must also be acquired. Young novice drivers must learn skills in car handling and essential maneuvers (starts, stops, turns, lane keeping, speed control, etc). Subsequently, competence in those skills must be achieved through practice, some in driver education, but mostly in supervised practice with an experienced driver (typically a parent for teens) over an extended period of time. Even when the basic knowledge and skills have been acquired, much experience is necessary for driving ability to become satisfactory. Crashes and offenses go down over time as novice drivers gain experience in the complex psychomotor task of driving. ${ }^{17-19}$

\section{Developmental factors}

For young people, developmental issues are prominent during the time they are learning to drive and during the early years of driving. Many young people, especially teens, are still developing and growing physically. Their hormones are "raging" and their energy levels are high. Recent research reveals that their brains may not be fully developed, perhaps until age 25, especially the prefrontal cortex where impulse inhibition, decision making, and judgment are centered..$^{20}$ The sleep patterns and needs of young people are also different from those of adults. Young people's biorhythms tend to demand that they go to sleep later at night and wake later in the morning than mature adults. Yet most high schools, to which many teens drive themselves, have early morning start times. ${ }^{21}$

In addition to the physical changes, several aspects of psychosocial development can affect young people's driving. Young drivers are still developing emotionally and seeking their identity as individuals, as well as evolving in their relationships with peers. Their social life and sexual identity are of keen importance to them. They are testing their limits and abilities while still developing. All these issues and factors are brought into the car with young people when they get behind the wheel and may affect their driving behavior.

Behavioral development is also a factor with youngsters who report early access to and use of tobacco, alcohol, and marijuana; this group has more evidence of risky driving, even drink/driving in their driving records. ${ }^{22-28}$ In addition, youngsters with better grades in school tend to have less risky driving. ${ }^{22} 26$

\section{Personality factors}

Several personality factors are related to risky driving among young people. Those with a risk taking propensity or sensation seeking personality are more likely to be involved in crashes (Patil SM, et al, unpublished data). ${ }^{29}{ }^{30}$ Those who exhibit tendencies toward hostility and aggression are also more likely to be involved in crashes (Patil SM, et al, unpublished data). And those who are more susceptible to peer pressure are likely to have more crashes. ${ }^{31}$ Another measure of interest is tolerance of deviance-the acceptance of behaviors that most others consider wrong or immoral. Those young people with a high tolerance of deviance (who 


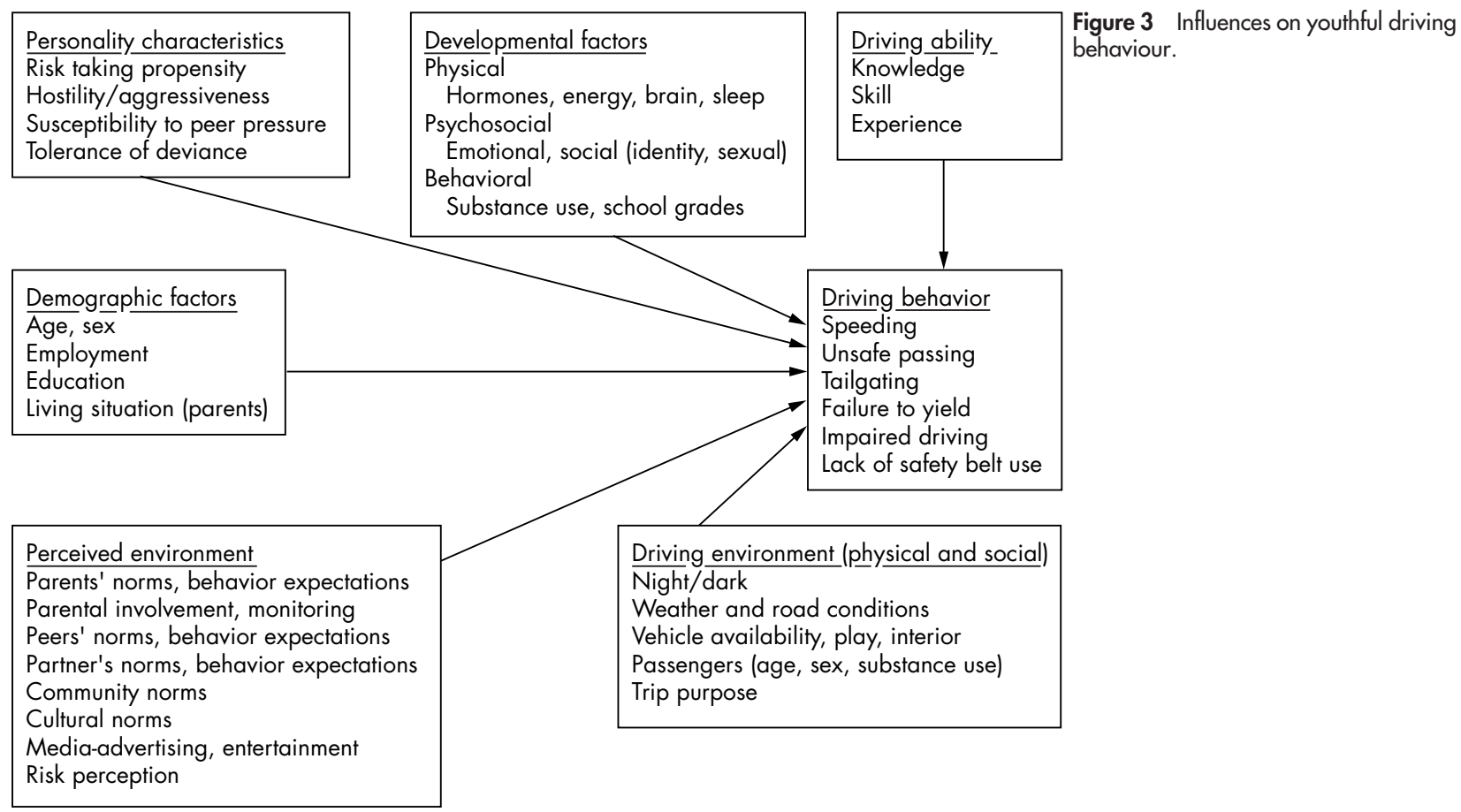

do NOT consider deviant behavior to be wrong) have more traffic crashes. ${ }^{22} 31-33$

\section{Demographic factors}

There are several demographic factors that are related to crashes. The youngest drivers have more crashes as mentioned earlier. ${ }^{6}$ Even though novice drivers in general have more crashes early on, age at licensure is also a contributor to crash risk, with younger licensees having more crashes. ${ }^{34}{ }^{35}$ Young male drivers are more likely to be involved in fatal crashes than young female drivers, ${ }^{5}$ and to engage in risky driving. ${ }^{36}$ Employment is related to driving behavior among young people in that those who are employed are more likely to report having driven after drinking. Among young adults in general, those with less education tend to show more driving problems, including drink/driving, but the relationship can be slightly different by sex and various levels of educational attainment. ${ }^{37}$ Young drivers who report that they live with both parents have less risky driving than those who live with only one parent, perhaps because of the ability of parents to monitor and be involved in their teens' behavior. ${ }^{24-26}$

\section{Perceived environment}

This category is perhaps the largest and most complex set of influences on youthful driving behavior. For his or her entire life, the young driver has been developing perceptions related to driving behaviors that are "normal" or expected, and these perceptions strongly influence how they drive. The first to be discussed will be perceptions that come from individuals in the young driver's personal life, followed by a discussion of perceptions that come from broader sources.

From birth on, most youngsters are driven around in a car by parents, and their perceptions about driving are being formed. Parents' driving is a strong influence on and example for the subsequent driving of a young person. People drive in ways similar to their parents. ${ }^{38}$ Parents' expectations of their young driver are also important, and when those are conveyed clearly and convincingly, those expectations can affect driving behavior. Parents who are involved in their young people's lives, who monitor, who nurture, who have high expectations, and who are not overly permissive, tend to have youngsters who drive with fewer crashes and offenses..$^{22-27} 32$ Other individuals who can influence young people's driving are their peers. It has already been mentioned that those who are susceptible to peer pressure have more offenses and crashes. ${ }^{31}$ Having friends involved early with alcohol is related to problem driving among teen drivers. ${ }^{24} 25$ The driving behavior of peers sets a norm that is an understandable influence on young drivers. Peer passengers can also influence young drivers' behavior, as seen in the negative influence of a young male passenger on male drivers, and the moderating effect of a young female passenger on drivers of both genders. ${ }^{39}$ In addition, the norms and expectations of a partner (girlfriend, boyfriend, significant other, or spouse) can have an important influence on driving behavior.

Beyond parents, peers, and partners is the wider world perceived by the young driver-that of the community, the culture, and the media. The young person's perception of driving risk is developed from these sources-how dangerous it is to drive, how likely a crash is, how likely it is that someone could get injured or killed, or how likely one is to get a ticket, be fined, or jailed for a particular driving infraction. Community norms and enforcement for driving behavior and how these are conveyed to young people will influence their perception of driving risk and, therefore, their driving. The US culture promotes car oriented expectations to young people, and not always in ways that promote the safest driving. Race car driving is a very popular sport and source of entertainment. The result is that even young teenagers expect to drive a car, own a car, and actually often need a car for transportation to meet basic needs. Some parents even purchase a car for their teen driver, and they may not purchase the safest or smartest vehicle for a young driver. ${ }^{40}$ The media, both advertising and entertainment, also promote fast driving and performance driving more than safe driving. Further, youngsters spend a lot of time with video games, many of which encourage aggressive behavior or car racing, with potential effects on young people's subsequent driving behavior. 


\section{Driving environment}

The environment in which young people drive, both its physical and social aspects, has several features that are related to subsequent risky driving. In terms of the physical environment, as mentioned earlier, driving at night (in the dark) is more risky for young people than for more mature drivers. ${ }^{6}$ While this finding may not be completely understood, it is an environmental factor of considerable importance. Bad weather and road types and conditions with which the young driver has had little experience may also present problems.

Teens' ownership of a vehicle is related to more driving and higher crash rates. ${ }^{40}{ }^{41}$ Further, teens who own vehicles tend to exhibit more risky driving behavior and traffic violations. ${ }^{4041}$ The type of vehicle being driven can also present problems to young drivers, who may not have gained the driving experience to handle SUVs, large vans, pick up trucks, etc. Having young novice drivers drive newer, heavier vehicles with more safety features may prevent injuries in case of a crash more so than older, smaller vehicles. ${ }^{41}$ Further, the physical aspects of the vehicle interior can be important. Being familiar with the vehicle controls, and having essentials such as sunglasses within easy reach is important. Finally, avoiding unsafe actions with food, beverages, cigarettes, cell phones, radios, and CD players are especially important for young novice drivers.

Little is known, but much can be imagined, about what is going on inside the vehicles driven by young drivers. This social context of their driving is an important influence on the outcome of risky driving, as the increased crash risk in the presence of passengers indicates. ${ }^{6}$ More risky driving is associated with being a teenager and being male. ${ }^{39}$ Social interaction very likely leads to distracting a young driver from the driving task. Social interaction such as conversation, or merely the presence of particular passengers, may also lead to different driving behaviors. The purpose of a driving trip has also been suspected of being related to risky driving. Trips to school, work, or to do errands may not lead to as much risky driving as trips for recreational or entertainment purposes.

\section{IMPLICATIONS FOR PREVENTION}

Potential interventions to prevent youthful driving behavior that may lead to crashes can target the driving behavior directly, or target one or more of the factors that influence the driving behavior. Some of these factors lend themselves to being changed more than others that should not be the target of interventions. The factors that cannot be changed can be used, however, to guide and inform interventions to prevent youthful risky driving.

\section{Driving behavior}

Driving behavior that is unsafe can be directly targeted by interventions through establishing and implementing policy. After legislation is passed, and laws implemented, however, the laws must be enforced to affect behavior. Enforcement should be certain, not allowing unsafe behavior to go unchecked, and it should be swift, not allowing delays to dilute the effect on subsequent behavior. Enforcement should also be consistent, not permitting the perception that the consequences will not happen to all drivers all the time. Obviously, this ideal is difficult to achieve, without, for instance, being able to implement such technology as red light or speed cameras that enforce particular behaviors certainly, swiftly, and consistently. Other new technology of interest would allow monitoring of teens' driving by parents, such that undesirable behavior could lead to consequences such as a loss of driving privileges, or desirable behavior could lead to an increase of driving privileges.

\section{Driving ability}

Ensuring that novice drivers have sufficient ability to drive independently is essential. Driver education and training is currently conducted in different ways, by different people, with different qualifications, and with different requirements for those qualifications. As mentioned earlier, a scientific basis for current practices may be lacking. ${ }^{16}$ It is important to identify what adequate education and training to drive should be, and then to require that. It is also important to determine scientifically what adequate practice and experience would be for licensure to drive independently, and then to require that as well. There is little current knowledge available, however, to do so. Without that knowledge, caution is certainly advisable before allowing teens who have had a driver education course to drive earlier than those who have not.

Traditional driver education courses may not adequately address lifestyle issues that are also related to risky driving. ${ }^{16}$ One program that attempted to do so was a high school based alcohol misuse prevention program that included refusal skills practice and had a positive effect on students' first year serious driving offenses. ${ }^{42}$

Graduated driver licensing (GDL) has been a key step in the right direction of helping teens develop their driving ability before being exposed to increasingly risky driving situations. States that do not have GDL should implement it, and states that have it should enhance their program to be the best possible. ${ }^{13}$ With or without GDL, parents of young people learning to drive should ensure that driving ability (knowledge, skill, and experience) is demonstrated through practice under different conditions. Privileges can be gradually granted as they are earned by teens exhibiting responsible independent driving.

\section{Developmental factors}

It is difficult to target developmental factors with an intervention, as they are, for the most part, not possible to change. But programs can take into account the developmental issues teens bring to the driving task. Licensing age could be reconsidered because of developmental factors. Developmental issues can also be a consideration as GDL programs are enhanced and parents' decisions regarding their own youngsters' driving are being made. Emotional development and maturity, as well as past behavior, as assessed by parents, could be a guide to decisions about teens' readiness to drive independently. Teens' sleep needs also could be considered in GDL program restrictions on new drivers, as well as in high schools' decision making regarding morning start times.

\section{Personality factors}

Personality is not usually considered possible to change but again could be considered by parents making decisions about their own teens' readiness to drive independently.

\section{Demographic factors}

Most demographic factors are not possible to change, but they could also be considered in decisions about readiness to drive independently. An older age of licensure may be desirable, but when considering sex, however, it is more complicated-should young men have to wait to drive longer than young women based on their higher crash numbers? Unfortunately, not enough is known about employment and driving among young teens to make suggestions.

\section{Perceived environment}

Several things could be done to target young people's perceptions about driving, gleaned from the environment in which they find themselves. Parents could be targeted to 
learn to set a good driving example and be the best role models. Parents can also be given assistance in learning ways to be more involved with their teens' driving and set more realistic restrictions on their novice teen drivers to enhance their safety. ${ }^{44}$ Creative programs are also needed that use peers and partners to promote safer driving by young people.

Communities could work to change their norms about young people's driving behavior-for example, sending clear, instead of mixed, messages about drink/driving. Changing the cultural norms about driving would be harder, although there is some current interest in the US overdependence on the automobile, the negative health effects of the built environment, energy use, and emissions. ${ }^{45}$ The media, both advertising and entertainment, could provide good avenues for interventions, although it may be challenging to enlist their collaboration. Risk perception can be changed, thus providing opportunities for intervention. Publicizing active traffic safety enforcement programs increases the perception of enforcement, thus resulting in safer driving behavior. ${ }^{46}$

\section{Driving environment}

Interventions have begun to target the driving environment, notably in the GDL night driving restriction. Restricting novice teen drivers from being exposed to the higher risk of late night driving until they have gained driving experience has been effective in reducing night-time crashes. ${ }^{47}{ }^{48}$ Parents can be encouraged to restrict novice teens' driving under certain weather and road conditions until their experience is adequate. Parents can also be advised about the risks associated with making a vehicle available to their teen, and the types of vehicles that would be safer for teens to drive. This ecologic approach has value and has also been used by GDL programs and by individual parents to restrict numbers of passengers and the age of passengers allowed to ride with a novice teen driver. Perhaps passenger sex should also be considered. Trip purpose has also been included in some GDL programs, usually to permit exceptions (not necessarily appropriately) to the program's restrictions.

\section{Successful interventions}

Successful interventions can be developed based on an understanding of the factors from the above conceptual framework. Interventions must be comprehensive to affect the complex issues involved in youthful driving behavior. Ideally, one would begin with interventions that are most likely to succeed, or that will effect the greatest difference in outcome. The framework presented can serve to guide the development of further research questions as well as interventions to be implemented and evaluated.

Further research will be needed to understand the viewpoints of young drivers themselves and their interpretations and explanations of the relationships in the framework, as well as their views of potential interventions. For instance, not wearing seat belts may serve a developmental purpose or function, such as "looking cool" for some young people. Interventions would not be successful without an understanding of the "purpose" of such a behavior, so that safer means to "be cool", for instance, could be promoted.

The intent of an intervention needs to be clear, and the expected outcome (not necessarily reduced crashes or changed driving behavior) identified. With a sound conceptual basis, interventions will be more likely to succeed, but of course they must be ongoing. If not, behaviors will return to pre-intervention levels. Successful interventions must also be ongoing because there are always new young drivers entering the driving population. And it may be that changing the behavior of a large group of people will be more easily accomplished with policy level changes rather than with individual behavioral approaches.
Evaluation of interventions is essential, and should include process evaluation as well as evaluation of the impact (on the intermediate measure of interest) and the outcome (driving behavior or crash). Ongoing research and evaluation of interventions may serve to add to and/or refine the conceptual framework presented. It is also important in intervention development to anticipate and monitor for unintended consequences, especially with young people. They can be very creative in reacting to well intentioned intervention efforts, resulting in surprising and often unanticipated outcomes.

\section{CONCLUSION}

It is important to study the issues and gather the evidence that links youthful driving behavior with the multiple factors that may influence that behavior-driving ability, development, personality, demographic factors, perceived environment, and the driving environment. Research may need to be conducted to fill in some gaps in existing knowledge. Recommendations for interventions should be based on research results in the conceptual framework. After interventions have been developed, implemented, and evaluated, revisions of the interventions will likely be necessary. After revisions, re-evaluation will be required.

Motor vehicle crashes due to young people's high risk driving behavior can be reduced. Doing so will require developing sound programs based on a conceptual framework such as that presented. Program implementation must then be thorough, and compliance with the program ensured. Parental involvement seems essential, and community involvement will enhance any program. Much has been learned about the factors related to high risk driving, and intervention programs can build on what is known while contributing further to the growing knowledge base being gathered for the purpose of protecting young drivers.

\section{ACKNOWLEDGEMENTS}

This paper was first presented as part of the first Expert Panel meeting of the Youthful Driver Research Initiative, a collaborative research program between the Center for Injury Research and Prevention (http://www.chop.edu/injury) at the Children's Hospital of Philadelphia (CHOP) (http://www.chop.edu) and State Farm Insurance Companies ${ }^{\circledR}$ (State Farm) (http://www.statefarm.com). The views presented in this paper are those of the author(s) and are not necessarily the views of CHOP or State Farm.

The author's previous work on which this paper is based has been supported in large part by NIH-NIAAA and NHTSA, and influenced by colleagues Patricia Waller, Ray Bingham, and Jennifer Zakrajsek.

Competing interests: none.

\section{About the author}

Jean Thatcher Shope is Research Professor and Associate Director at the University of Michigan Transportation Research Institute (UMTRI), where she has conducted young driver research since 1991. She has been on the faculty of the Department of Health Behavior and Health Education in the University of Michigan School of Public Health since 1979. Dr Shope has a BSN degree from Cornell University, an MSPH from the University of Minnesota, and a PhD from Wayne State University in the Theoretical and Behavioral Foundations of Education. She also completed a postdoctoral fellowship in Health Behavior and Health Education in the University of Michigan School of Public Health. Dr Shope is an appointed member of the National Research Council Transportation Research Board's Committee on Alcohol, Other Drugs, and Transportation. 


\section{REFERENCES}

1 Williams AF. Next steps for graduated licensing. Traffic Inj Prev 2005;6:199-201.

2 National Highway Traffic Safety Administration. Traffic safety facts 2004, Available at http://www-nrd.nhtsa.dot.gov/pdf/nrd-30/NCSA/TSFAnn/ TSF2004.pdf (accessed February 2006)

3 National Highway Traffic Safety Administration. Traffic safety facts 2002, Available at http://www-nrd.nhtsa.dot.gov/pdf/nrd-30/NCSA/TSF2002/ 2002ydrfacts.pdf (accessed February 2006).

4 Winston FK, Rineer C, Menon R, et al. The carnage wrought by major economic change: Ecological study of traffic related mortality and the reunification of Germany. BMJ 1999;318:1647-50.

5 Insurance Institute for Highway Safety. Fatality facts 2004: teenagers, Available at http://www.iihs.org/research/fatality_facts/teenagers.html (accessed February 2006).

6 Williams AF. Teenage drivers: patterns of risk J Safety Res 2003:34:5-15.

7 Zador PL, Krawchuk SA, Voas RB. Alcohol-related relative risk of driver fatalities and driver involvement in fatal crashes in relation to driver age and gender: an update using 1996 data. J Stud Alcohol 2000;61:387-95.

8 In: Glanz K, Lewis FM, Rimer BK, eds. Health behavior and health education. San Francisco, CA: John Wiley \& Sons, Inc, 2002.

9 Jessor R. Risk behavior in adolescence: a psychosocial framework for understanding and action. J Adolesc Health 1991;12:597-605.

10 Shope JT, Bingham CR. Drinking-driving as a component of problem driving and problem behavior in young adults. J Stud Alcohol 2002;63:24-33.

11 Jonah BA. Accident risk and risk-taking behaviour among young drivers. Accid Anal Prev 1986;18:255-71.

12 Williams AF, Ferguson SA. Rationale for graduated licensing and the risks it should address. Inj Prev 2002;8(Suppl II):ii9-iil6.

13 Fisher DL, Laurie NE, Glaser R, et al. Use of a fixed-base driving simulator to evaluate the effects of experience and PC-based risk awareness training on drivers' decisions. Human Factors 2002;44:287-302

14 Wolfson AR, Carskadon MA. Sleep schedules and daytime functioning in adolescents. Child Dev 1998;69:875-87.

15 Greenberg J, Tijerina L, Curry R, et al. Driver distraction-evaluation with event detection paradigm. Transportation Research Record 2003;1843:1-9.

16 Mayhew DR, Simpson HM. The safety value of driver education and training Inj Prev 2002;8(Suppl II):ii3-ii8.

17 Mayhew DR, Simpson HM, Pak A. Changes in collision rates among novice drivers during the first months of driving. Accid Anal Prev 2003:35:683-91.

18 McCartt AT, Shabanova VI, Leaf WA. Driving experience, crashes and traffic citations of teenage beginning drivers. Accid Anal Prev 2003;35:31 1-20.

19 Waller PF, Elliott MR, Shope JT, et al. Changes in young adult offense and crash patterns over time. Accid Anal Prev 2001;33:117-28.

20 Paus T. Mapping brain maturation and cognitive development during adolescence. Trends Cogn Sci 2005;9:60-8.

21 National Sleep Foundation. Adolescent sleep needs and patterns, Available at http://www.sleepfoundation.org/_content/hottopics/ sleep and teens reportl.pdf (accessed February 2006)

22 Bingham CR, Shope JT. Patterns of traffic offenses from licensure into early young adulthood. J Adolesc Health (in press).

23 Copeland LA, Shope JT, Waller PF. Factors in adolescent drinking/driving: binge drinking, cigarette smoking, and gender. J Sch Health 1996;66:254-60

24 Lang SW, Waller PF, Shope JT. Adolescent driving: characteristics associated with single-vehicle and injury crashes. J Safety Res 1996;27:241-57.

25 Shope JT, Waller PF, Lang SW. Alcohol-related predictors of adolescent driving: gender differences in crashes and offenses. Accid Anal Prev 1996;28:755-64.

26 Shope JT, Waller PF, Lang SW. Adolescent crashes and offenses by gender: implications for prevention. Proceedings of the 14th International Conference on Alcohol, Drugs and Traffic Safety. Annecy, France: Conference on Alcohol, Drugs and Traffic Safety, 1997;1:449-56.

27 Shope JT, Waller PF, Raghunathan TE, et al. Adolescent antecedents of highrisk driving behavior in young adulthood: substance use and parental influences. Accid Anal Prev 2001:33:649-58.

28 Shope JT, Zakrajsek JS. Age of drinking onset predicts young adults' selfreported drink-driving. 16th International Conference on Alcohol, Drugs, and Traffic Safety. Montreal, QB, Canada: Conference on Alcohol, Drugs and Traffic Safety, 2002;CD-ROM)

29 Jonah BA. Sensation seeking and risky driving: a review and synthesis of the literature. Accid Anal Prev 1997;29:651-65.

30 Zuckerman $M$, Neeb $M$. Demographic influences in sensation seeking and expressions of sensation seeking in religion, smoking and driving habits. Pers Individ Dif 1980;1:197-206.

31 Shope JT, Raghunathan TE, Patil SM. Examining trajectories of adolescent risk factors as predictors of subsequent high-risk driving behavior. J Adolesc Health 2003;32:214-24.

32 Bingham CR, Shope JT. Adolescent developmental antecedents of risky driving among young adults. J Stud Alcohol 2004;65:84-94.

33 Bingham CR, Shope JT. Adolescent problem behavior and problem driving in young adulthood. J Adolesc Res 2004; 19:205-23

34 Elliott MR, Raghunathan TE, Shope JT. The effect of duration of licensure on risk of crash: a Bayesian analysis of repeated time-to-event measures. J Am Stat Assoc 2002;97:420-31.

35 Williams AF, Karpf RS, Zador PL. Variations in minimum licensing age and fatal motor vehicle crashes. Am J Public Health 1983;73:1401-3.

36 Elliott MR, Shope JT, Raghunathan TE, et al. Gender differences among young drivers in the association between high-risk driving and substance use/ environmental influences. J Stud Alcohol 2006;67:252-60.

37 Bingham CR, Shope JT, Tang X. Drinking behavior from high school to young adulthood: differences by college education. Alcohol Clin Exp Res 2005;29:2170-80.

38 Ferguson SA, Williams AF, Chapline JF, et al. Relationship of parent driving records to the driving records of their children. Accid Anal Prev 2001;33:229-34.

39 Simons-Morton B, Lerner N, Singer J. The observed effects of teenage passengers on the risky driving behavior of teenage drivers. Accid Anal Prev 2005;37:973-82

40 Cammisa MX, Williams AF, Leaf WA. Vehicles driven by teenagers in four states. J Safety Res 1999;30:25-30.

41 Williams AF, Leaf WA, Simons-Morton BG, et al. Vehicles driven by teenagers in their first year of licensure. Traffic Inj Prev 2006;7:23-30

42 Shope JT, Elliott MR, Raghunathan TE, et al. Long-term follow-up of a high school alcohol misuse prevention program's effect on students' subsequent driving. Alcohol Clin Exp Res 2001;25:403-10.

43 Williams AF, Ferguson SA, Wells JK. Sixteen-year-old drivers in fatal crashes, United States, 2003. Traffic Inj Prev 2005;6:202-6.

44 Simons-Morton BG, Hartos JL, Leaf WA, et al. Persistence of effects of the Checkpoints program on parental restrictions of teen driving privileges. Am J Public Health 2005:95:447-52.

45 Jackson RJ. The impact of the built environment on health: an emerging field. Am J Public Health 2003;93:1382-3.

46 National Highway Traffic Safety Administration. Evaluation of Click It or Ticket model programs. Available at http://www.nhtsa.gov/people/injury/ airbags/clickit_ticket/clickitcomposite/clickit_composite.pdf (accessed February 2006).

47 Foss RD, Feaganes JR, Rodgman EA. Initial effects of graduated driver licensing on 16-year-old driver crashes in North Carolina. JAMA 2001;286:1588-92.

48 Shope JT, Molnar $\sqcup$. Michigan's graduated driver licensing program: evaluation of the first four years. J Safety Res 2004;35:337-44. 